\title{
Partisipasi Masyarakat Dalam Pengelolaan Desa Wisata Bongkasa Pertiwi Di Kabupaten Badung
}

Ni Made Devy Karnayanti a,1, I Gusti Agung Oka Mahagangga a,2

${ }^{1}$ kadekdevy97@gmail.com, ${ }^{2}$ okamahagangga@unud.ac.id

a Program Studi Sarjana Destinasi Pariwisata, Fakultas Pariwisata,Universitas Udayana, Jl. Dr. R. Goris, Denpasar, Bali 80232 Indonesia

\begin{abstract}
The purpose of this research is to know community participation in managing Bongkasa Pertiwi Village in Badung Regency. In this study using primary data sources and secondary data sources, while the type of data used is qualitative data. Methods of data collection through observation, interview and documentation study. Determination of informants in this study using purposive sampling technique. Data analysis used is qualitative data analysis technique and constrained by $4 A$ concept, rural tourism concept, management concept and society participation concept. The research results obtained is Public participation is not optimal in managing tourist village, lack of public participation in planning, organizing, implementation and supervision because of the weakness of role of tourism village manager, low quality of human resources, socio-economic life of the community and lack of cooperation.
\end{abstract}

Keywords: Rural Tourism, Management, Community Participation

\section{PENDAHULUAN}

Menurut Undang-undang R.I. No.10 Tahun 2009 tentang Kepariwisataan, yang mengamanatkan bahwa kepariwisataan merupakan bagian integral dari pembangunan nasional yang diilakukan secara sistematis, terencana, terpadu, berkelanjutan, dan bertanggung jawab dengan tetap memberikan perlindungan terhadap nilai-nilai agama, budaya yang hidup dalam masyarakat, kelestarian dan mutu lingkungan hidup, serta kepentingan nasional.

Seperti halnya Kabupaten Badung, berdasarkan Peraturan Bupati Badung Nomor 47 Tahun 2010 tentang Penetapan Kawasan Desa Wisata maka Kabupaten Badung memiliki 11 desa wisata sebagai wisata alternatif bagi wisatawan. Dengan ditetapkannya desa wisata tersebut yang tersebar di beberapa wilayah di Kabupaten Badung, terutama di bagian Badung Utara diharupkan agar adanya pemerataan sektor pariwisata yang tidak hanya dipusatkan ke Badung Selatan.

Desa wisata didefinisikan sebagai sebagian atau seluruh wilayah desa yang memiliki potensi, aktivitas wisata dan produk wisata yang dapat dimanfaatkan untuk pengembangan pariwisata yang dikelola oleh masyarakat di suatu desa secara berkelanjutan dan berbasis masyarakat. Salah satu desa yang termasuk ke dalam Badung bagian tengah yaitu, Desa Wisata Bongkasa Pertiwi yang mana memiliki potensi alam dan budaya yang menjadi ciri khas tersendiri dari desa wisata ini.

Kunjungan wisatawan ke Desa Bongkasa Pertiwi yang semakin meningkat setiap tahunnya untuk melakukan kegiatan pariwisata, oleh karena itu Pemerintah Kabupaten Badung menetapkan desa ini sebagai desa wisata, namun dalam perkembangannya dari perencanaan, kelembagaan, persiapan masyarakat maupun sisi produk wisata tersebut kurang memadai.

Hal ini diindikasikan dengan minimnya keikutsertaan masyarakat lokal dalam pengelolaan maupun mendampingi jalannya pengembangan desa wisata ini dan yang lebih buruk lagi terdapat masyarakat yang hanya mengetahui ditetapkannya desa wisata tanpa tahu kegiatan yang ada di dalamnya. Meskipun di sisi lain, kucuran dana untuk meningkatkan pelayanan pariwisata, seperti dibangunnya fasilitas parkir, dan toilet untuk wisatawan sudah dilakukan oleh pemerintah Kabupaten Badung. Oleh karena itu fokus penelitian ini adalah bagaimana partisipasi masyarakat dalam pengelolaan Desa Wisata Bongkasa Pertiwi di Kabupaten Badung. Tujuan penelitian ini adalah Untuk mengetahui partisipasi masyarakat dalam pengelolaan Desa Wisata Bongkasa Pertiwi di Kabupaten Badung. 


\section{TINJAUAN PUSTAKA}

Telaah penelitian yang dilakukan sebelumnya sangat penting untuk membandingkan antara penelitian sebelumnya dengan penelitian yang akan dilakukan. Penelitian pertama dilakukan oleh Arida, dkk (2014). Penelitian tersebut berjudul "Keterlibatan Masyarakat Dalam Pengelolaan Desa Wisata Pangsan di Kabupaten Badung”. Lalu penelitian kedua yang dijadikan acuan ialah penelitian yang dilakukan oleh Setiawan dkk (2016) penelitian tersebut berjudul "Strategi Pengembangan Desa Bongkasa Pertiwi Kabupaten Badung Sebagai Desa Wisata". Penelitian ketiga yaitu oleh Mahagangga, dkk (2015) penelitian yang berjudul "Kajian Pengembangan Desa Wisata di Kabupaten Badung".

Penelitian ini menggunakan konsep Desa Wisata merujuk pada Pitana (Pitana,1994:52), konsep community based tourism (Suansri,2003), konsep partisipasi masyarakat (Apsari,2005), konsep pengelolaan dalam Terry (Terry,2006:342) dan teori partisipasi (Tosun,1999).

\section{METODE PENELITIAN}

Penelitian ini mengambil batasan lokasi di Desa Bongkasa Pertiwi Kecamatan Abiansemal, Kabupaten Badung, Provinsi Bali. Desa Bongkasa Pertiwi merupakan desa pemekaran dari Desa Bongkasa yang terdiridari 3 banjar didalamnya yaitu, Banjar Tegal Kuning, Banjar Karang Dalem I dan Banjar Karang Dalem II. Lokasi penelitian ini berjarak $\pm 45 \mathrm{~km}$ dari Bandara Internasional Ngurah Rai dengan jarak tempuh sekitar 1 jam 45 menit.

Jenis data dalam penelitian ini menggunakan jenis data kualitatif $\mathrm{p}$ deskripsi mengenai berupa partisipasi masyarakat dalam pengelolaan Desa Wisata Bongkasa Pertiwi dikaji melalui pengelolaan desa wisata mulai dari perencanaan, pengorganisasian, penggerakan dan pengawasan.

Teknik pengumpulan data dalam penelitian ini menggunakan teknik observasi, wawancara dari Bungin (2003) dan dokumentasi dari indrawan (2014).

Sumber data yang digunakan dalam penelitian ini adalah data primer dan data sekunder. Data primer berupa masyarakat desa yang berpartisipasi dan masyarakat desa setempat yang tidak berpartisipasi Data sekunder dalam penelitian ini berupa monografi Desa Wisata Bongkasa Pertiwi.

Teknik analisis data dalam penelitian ini menggunakan teknik analisis data kualitatif (Seiddel dalam Moleong, 2012).

\section{HASIL DAN PEMBAHASAN}

Adapun hasil dan pembahasan dalam tulisan ini adalah sebagai berikut.

\section{Gambaran Umum Desa Bongkasa Pertiwi}

Desa Bongkasa Pertiwi merupakan suatu daerah yang termasuk dataran tinggi dengan ketinggian $312 \mathrm{~m}$ dari permukaan laut, beriklim tropis lembab dengan curah hujan hampir 2000$3000 \mathrm{~mm} /$ enam bulan. Desa yang merupakan dataran tinggi dengan potensi alam pedesaan, terdapat sungai besar yaitu sungai Ayung di sebelah Timur Desa, dengan luas wilayah 157,00 Ha, dan terdapat subak yang mengatur irigasi persawahan di Desa ini yang dibagi menjadi 2 munduk yaitu Subak Karang Dalem I dan Subak Batu Megong dengan masing-masing luas $30 \mathrm{Ha}$ dan $40 \mathrm{Ha}$.

Desa ini ditetapkan sebagai desa wisata menurut SK Bupati Badung Nomor 47 Tahun 2010 tentang penetapan Kawasan Desa Wisata di Kabupaten Badung. Dengan ditetapkannya Desa Bongkasa Pertiwi sebagai Desa Wisata, maka dibentuklah Kelompok Sadar Wisata Bongkasa Pertiwi berdasarkan Surat Keputusan Perbekel Bongkasa Pertiwi Nomor : 11 Tahun 2009 pada tanggal 14 Mei 2009. Kelompok Sadar Wisata Bongkasa Pertiwi sebagai wadah untuk meningkatkan kesadaran masyarakat akan pentingnya pengelolaan Desa Wisata dan juga merupakan mitra kerja pemerintah Kabupaten Badung dalam upaya meningkatkan pengembangan desa wisata serta keikutsertaan masyarakat di dalamnya.

Potensi alam berupa Sungai ayung, persawahan, dan tebing. Potensi budaya seperti tari calonarang, perang sambuk, tari tari kunti sraya, pengrajin perak, gotong royong dan keramahtamahan masyarakat yang masih dijaga. 
Adapun kondisi eksisting dari Desa Wisata Bongkasa Pertiwi adalah sebagai berikut.

a. Attraction (Atraksi)

Kegiatan tersebut yaitu, Paintball,Atv, Arung Jeram (Rafting), dan Bali Swing.

b. Amenity (Fasilitas)

Fasilitas penunjang berupa, 4 pondok wisata, warung makanan dan minuman, pramuwisata, fasilitas kesehatan (puskesmas), fasilitas parkir.

c. Accessibility (Aksesibilitas)

Akses wisatawan ke Desa Wisata Bongkasa Pertiwi yang hanya berjarak sekitar $2,5 \mathrm{~km}$ dari pusat kota Ubud. Selain itu, keadaan jalan yang baik serta akses jalan yang terbagi menjadi 2 di sebelah barat dan timur.

d. Ancillary (Pelayanan Tambahan)

Dalam mendukung penyelenggaraan desa wisata di Desa Bongkasa Pertiwi terdapat lembaga yang pengelolaan desa wisata yang disebut POKDARWIS (Kelompok Sadar Wisata).

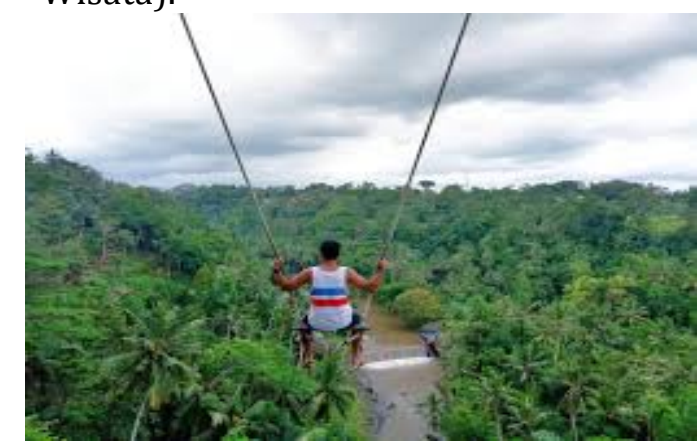

Gambar 1. Kegiatan Atraksi Wisata di Desa Wisata Bongkasa Pertiwi

Sumber : $\quad$ Bali Swing,2018

\section{Pengelolaan Desa Wisata Bongkasa Pertiwi}

Dengan adanya desa wisata diharapkan masyarakat dapat ikut terlibat dan berpartisipasi dalam pengelolaan Desa Wisata Bongkasa Pertiwi, mengingat potensi alam dan potensi budaya yang ada saat ini.

a. Perencanaan awal pembentukan Desa Wisata Bongkasa Pertiwi

1. Tahap Identifikasi Masalah dan Potensi pengembangan wisata

Sebelum ditetapkan sebagai desa wisata,

Desa Bongkasa Pertiwi merupakandesa yang merupakan hasil pemekaran dari Desa Bongkasa. Pada tahap perencanaan pihak desa beserta pengelola memiliki program yaitu, penyediaan akomodasi, pengolahan limbah babi dan air bersih, pelatihan kuliner ibu PKK desa, atraksi trekking dan pembangunan perusahaan arum jeram milik desa.

2. Tahap Sosialisasi

Dalam mensosialisasikan Desa Bongkasa Pertiwi sebagai desa wisata, dilakukan musyawarah desa atau di Bali dikenal dengan sangkep. Melalui musyawarah desa, pihak elit desa yang melalui perantara Kelian Banjar atau Kepala Banjar di tiga banjar yaitu Banjar Karang Dalem I, Karang Dalem II dan Tegal Kuning, diumumkan bahwa sesuai SK Bupati Badung tahun 2010, Desa Bongkasa Pertiwi sebagai desa wisata.

b. Pengorganisasian Lembaga pengelola Desa Wisata Bongkasa Pertiwi

1. Tahap Pengembangan Rencana Fasilitas

Pembentukan lembaga yang bertugas pengelolaan Desa Wisata Bongkasa Pertiwi ditunjuk sesuai dengan profesi atau pengalaman di bidang pariwisata. Pemilihan ketua dan anggota di dilakukan melaui musyawarah desa dengan mengajukan perwakilan dari masing-masing banjar hal ini seperti yang diungkapkan oleh I Wayan Martana, sebagai berikut :

"ditetapkan sebagai desa wisata dibentuklah kelompok sadar wisata yang langsung dipilih dari perwakilan masing-masing banjar untuk ikut dalam organisasi,anggota yang ditunjuk kebanyakan yang berkecimpung di pariwisata"

(wawancara tanggal 27 April 2018).

Adapun lembaga yang ada tersebut yaitu POKDARWIS (Kelompok Sadar Wisata) dibentuk pada tahun 2009 dengan anggota berjumlah 15 orang yang kini dibentuk kembali melalui musyawarah pembentukan dan penetapan pengurus Desa Wisata Bongkasa Pertiwi yang dihadiri oleh Perbekel (Kepala Desa), Tokoh Masyarakat dan calon pelaku pengurus desa wisata pada bulan Juni Tahun 2017 dengan total anggota 18 orang 
dapat dilihat pada Struktur Organisasi POKDARWIS.

Kedua, fasilitas pelayanan (amenitas) dengan ditetapkannya sebagai desa wisata, Desa Bongkasa Pertiwi terjadi perubahan fisik seperti adanya pelebaran aspal, perbaikan aspal, pembangunan fasilitas parkir dan toilet, adanya pelang nama Desa Wisata Bongkasa Pertiwi, papan penunjuk arah, penamaan jalan, dan fasilitas pendukung lainnya.

Ketiga yaitu promosi. Kegiatan promosi bekerjasama dengan dinas pariwisata Provinsi Bali, ASITA. Selain itu juga pihak desa membuat sebuah video mengenai desa Bongkasa Pertiwi yang dipublikasikan melalui Youtube.

2. Pelaksanaan Program Desa Wisata Bongkasa Pertiwi

Dalam rangka pelaksanaan program wisata yang telah direncanakan sebelumnya, diperlukan kerjasama dengan berbagai pihak yang terlibat didalamnya. Adanya kerjasama POKDARWIS, BUM Desa dan masyarakat dalam pelaksanaan program sesuai tugas dan tanggung jawabnya.

3. Pengawasan dan evaluasi kegiatan Desa Wisata Bongkasa Pertiwi

Dengan berjalannya program yang dilaksanakan diawasi oleh Kepala Desa sendiri yaitu I Made Suarjana dan bagian pengawas dari BUM Desa agar tidak menyimpang dengan kesepakatan dan aturan desa yang dibuat. Lalu diadakan rapat evaluasi berkumpul bersama untuk membahas mengenai kekurangan dan kendala yang dihadapi dalam kegiatan tersebut yang nantinya dapat diberikan solusinya.

Berdasarkan pasar utama wisatawan yang disasar Desa Wisata Bongkasa Pertiwi yaitu wisatawan mancanegara yang menyukai alam dan budaya. Salah satunya wisatawan yang berasal dari Amerika dan wisatawan Australia karena dari karakteristiknya wisatawan yang berasal dari Amerika dan Australia merupakan wisatawan yang mudah bergaul dan lebih menyukai keindahan alam, budaya serta tipe kunjungannya tidak berkelompok.

\section{Partisipasi Masyarakat dalam Pengelolaan Desa Wisata Bongkasa Pertiwi}

Sebagai komponen utama dalam pengembangan desa wisata community based tourism (CBT), peran masyarakat sangat penting khususnya pengelolaan desa wisata tidak bisa diabaikan begitu saja, karena masyarakat lokal merupakan orang pertama yang mengetahui keadaan dari daerahnya dibandingkan masyarakat luar desa baik dalam perencanaan, pengembangan, pengelolaan maupun evaluasi kerja.

a. Partisipasi Masyarakat dalam Tahap
$\begin{gathered}\text { Perencanaan } \\ \text { Partisipasi masyarakat dalam tahap }\end{gathered}$ perencanaan hanya sebatas dukungan ditetapkannya sebagai desa wisata, dukungan yang diberikan berupa solidaritas masyarakat menerima rencana yang sebelumnya pengambilan keputusan dilakukan oleh pihakk elite desa, disampaikan oleh pihak elite desa. Terlihat dari tidak dilibatkannya masyarakat dalam proses perencanaan seperti yang diungkapkan oleh Kepala POKDARWIS

"memang waktu memetakan potensi alam dan kebudayaan yang ada dilakukan oleh saya sendiri, staff elite desa, pak klian dinas yang mengerti pariwisata, kalau mengajak seluruh masyarakat kan susah jadinya. Jadi hanya beberapa masyarakat yang berkecimpung di pariwisata yang diajak seperti tokoh masyarakat, guide tetapi setelah itu disampaikan kepada masyarakat melalui rapat desa".

(wawancara 27 April 2018).

Dari pemaparan tersebut dapat ditinjau bahwa dalam tahap perencanaan Desa Wisata Bongkasa Pertiwi aktor yang terlibat ialah, tokoh masyarakat, POKDARWIS, BUM Desa, Pemerintah Desa, Kepala Banjar di ketiga Banjar, dibantu Dinas Pariwisata Provinsi Bali dalam memetakan potensi alam dan budaya. Partisipasi seperti ini sebagai partisipasi pasif (passive participation) yaitu masyarakat hanya dilibatkan dalam pelaksanaan namun tidak dilibatkan saat pengambilan keputusan. 
b. Partisipasi Masyarakat pada Tahap

Pengorganisasian

Dalam proses pengorganisasian dibentuk POKDARWIS (Kelompok Sadar Wisata). Dimana termuat dalam SK pembentukan pengurus Desa Wisata Bongkasa Pertiwi menyebutkan,

"telah dilaksanakan musyawarah pembentukan dan penetapan pengurus Desa Wisata Bongkasa Pertiwi yang di hadiri oleh Perbekel, Tokoh Masyarakat dan calon anggota pelaku desa wisata".

(wawancara 28 April 2018).

Penuturan dari salah satu masyarakat yaitu Yudis (45) pedagang di Karang Dalem I

"kalau organisasi yang dalam desa wisata yang saya tau itu pokdarwis, tapi mengenai perekrutan anggota dan lain-lainnya pihak desa yang tahu, saya kurang tahu soal itu "

(wawancara 22 April 2018).

Partisipasi masyarakat dalam pengorganisasian termasuk partisipasi tidak langsung (indirect participation) yang mana masyarakat Desa Bongkasa Pertiwi tidak mengalami sendiri dan keputusan yang diambil tidak disampaikan langsung bahwa akan membentuk sebuah lembaga yang pengelolaan desa wisata melainkan hanya menunjuk salah satu masyarakat yang dilihat mumpuni di bidang pariwisata.

c. Partisipasi Masyarakat pada Tahap Pelaksanaan

Dalam pelaksanaan program desa wisata belum seluruh masyarakat yang berpartisipasi, hanya sebagian dari masyarakat Desa Bongkasa Pertiwi yang sadar untuk ikut berpartisipasi dalam membangun desa wisata. Masyarakat lebih memilih bekerja diluar desa, seperti yang diungkap pengelola desa wisata I Wayan Martana:

" masyarakat belum sadar dan paham dengan potensi yang ada di desanya, mereka menganggap kerja di desa hasilnya sedikit"

(wawancara 28 April 2018).

Keterlibatan masyarakat dalam pengelolaan akomodasi yakni dibangunnya 4 buah pondok wisata dengan menggunakan arsitektur Bali, pembentukan POKDARWIS yang anggotanya direkrut dari perwakilan masingmasing banjar, keterlibatan masyarakat dalam pelatihan penyediaan kuliner oleh ibu PKK (Pembinaan Kesejahteraan Keluarga). Seperti yang dituturkan oleh seorang masyarakat lokal Desa Wisata Bongkasa Pertiwi yaitu Ni Nengah Sukasih (30) yang bekerja sebagai pedagang :

"sosialisasi dan pelatihan desa wisata ada, seperti latihan membuat kue-kue tetapi saya tidak mengikuti karena tidak ada waktu, sibuk berdagang"

(wawancara 22 April 2018).

Dari pemaparan Ni Nengah Sukasih tersebut bahwa partisipasi masyakarat belum optimal dalam pelaksanaan kegiatan desa wisata, dengan keterbatasan waktu serta kegiatan tersebut bukan merupakan kegiatan prioritas dari masyarakat yang tidak ikut berpartisipasi.

Partisipasi masyarakat dalam pelaksanaan program wisata berupa partisipasi terdorong ( induced participation) oleh POKDARWIS yang mana masyarakat berpartisipasi dalam pengelolaan akomodasi, keterlibatan dalam pelatihan/peningkatan kualitas wisata, keterlibatan pengelolaan fasilitas (amenity).

d. Partisipasi Masyarakat Pada Tahap Pengawasan

Partisipasi masyarakat dalam pengawasan kegiatan wisata di Desa Wisata Bongkasa Pertiwi selama ini berjalan sesuai asas kekeluargaan atau informal dimana apabila terdapat kejanggalan atau permasalahan mengenai kegiatan wisata yang ada disampaikan kepada salah satu Kepala Desa Bongkasa Pertiwi, Kepala Pokdarwis atau Kepala Banjar di masing-masing banjar. Seperti yang diungkapkan oleh salah satu masyarakat lokal yaitu I Wayan Suweja (48) seorang guide

"kalau pengawasan tentang kegiatan wisata dilakukan oleh Kepala Desa biasanya dan elite desa lainnya, tapi kalau dari masyarakat palingan hanya melapor apabila ada perusahaan rafting yang akan menggunakan tempat parkir milik desa, laporan bahwa ada wisatawan asing yang menginap di villa ke 


\section{Sekretaris Desa yang sekaligus Kepala POKDARWIS “}

(wawancara 27 April 2018).

Dalam hal ini dapat diketahui bahwa partisipasi masyarakat Desa Wisata Bongkasa Pertiwi berupa partisipasi tidak langsung (indirect participation) yang mana masyarakat apabila ada kegiatan atau pengembangan yang tidak sesuai dengan aturan yang disepakati maka disampaikan secara informal baik ke Kepala Desa maupun pihak pengelola. Oleh karena itu dalam pengawasan kegiatan wisata di desa ini masih belum optimal.

\section{Hambatan yang Dialami Masyarakat dalam Partisipasi Pengelolaan Desa Wisata}

Dalam proses pengelolaan Desa Wisata Bongkasa Pertiwi terdapat banyak kendala yang dihadapi yaitu,

\section{a. Badan Pengelola Desa Wisata}

Masih lemahnya peran pengelola menjadi faktor utama penghambat berkembangnya suatu desa wisata. Selain itu juga, dorongan semangat dan keaktifan di dalam organisasi ini masih minim dan keterbatasan dana juga menjadi alasan belum optimalnya proses pelatihan dan sosialisasi kepada masyarakat mengenai desa wisata.

\section{b. Sumber Daya Manusia}

Kurangnya kesadaran dan pemahaman masyarakat dan generasi muda khususnya akan manfaat yang diperoleh dari kegiatan desa wisata menyebabkan mereka lebih memilih bekerja di luar desa maupun di luar daerah dengan penghasilan yang pasti, tanpa diketahui apabila generasi muda yang menjalankan pengembangan desa wisata memberikan kontribusi positif dan tentunya akan berkelanjutan.

\section{c. Kehidupan Sosial Ekonomi Masyarakat}

Kehidupan sosial masyarakat yang sebagian besar bermata pencaharian petani menjadikan pola pikir yang dimiliki masih tradisional dalam memahami perkembangan pariwisata di desanya saat ini serta keterbatasan waktu masyarakat yang memprioritaskan pekerjaan lainnya daripada mengelola desa yang sudah ditetapkan sebagai desa wista. d. Kurangnya Kerjasama dengan Instansi Terkait.

Sampai saat ini belum ada travel agent yang bekerjasama dengan pihak desa yang nantinya dapat meningkatkan kunjungan wisatawan untuk menikmati atraksi yang dimiliki desa wisata.

\section{SIMPULAN DAN SARAN}

Berdasarkan hasil penelitian tentang partisipasi masyarakat dalam pengelolaan Desa Wisata Bongkasa Pertiwi di Kabupaten Badung diperoleh hasil, terdapat atraksi wisata berupa, Paintball dan Atv, Perusahaan Arung Jeram dan Swing. Fasilitas yaitu, akomodasi atau penginapan berupa 4 pondok wisata dan 2 villa, pramuwisata, Fasilitas Kesehatan Puskesmas dan fasilitas parkir yang dilengkapi toilet didalamnya. Aksesibilitas dengan keadaaan jalan yang beraspal, terdapat jasa transportasi berupa taxi, dan akses menuju persawahan berupa jalan paving. Pelayanan tambahan terdapat lembaga yang pengelolaan desa wisata yaitu POKDARWIS,

Dari hasil penelitian dan pembahasan diatas partisipasi masyarakat dalam pengelolaan Desa Wisata Bongkasa Pertiwi termasuk ke dalam partisipasi masyarakat terdorong (induced participation). Hal tersebut dikarenakan adanya bujukan atau dorongan dari pihak pemerintah, swasta, kepala desa maupun kelompok sadar wisata terhadap masyarakat untuk ikut terlibat dalam pengelolaan desa wisata.

Dalam pengelolaan Desa Wisata Bongkasa Pertiwi terdapat kendala yang dihadapi yaitu, masih lemahnya peran badan pengelola desa wisata, rendahnya kualitas sumber daya manusia, kehidupan sosial ekonomi masyarakat dan kurangnya kerjasama dengan instansi terkait.

Adapun saran yang dapat diberikan terkait partisipasi masyarakat dalam pengelolaan Desa Wisata Bongkasa Pertiwi Kepada pihak Pemerintah, perlunya motivasi, bantuan berupa dana, dan pelatihan-pelatihan rutin kepada pengelola dan masyarakat. Kepada Pengelola dan Pemerintah Desa, untuk membuat visi dan misi dari organisasi POKDARWIS dan melakukan pelatihan-pelatihan yang intensif dalam mengemas produk wisata sesuai dengan potensi yang ada serta menjalin kerjasama dengan agen perjalanan. Kepada masyarakat Desa Bongkasa 
Vol. 7 No 1, 2019

Pertiwi agar tetap mempertahankan dan menjaga alam dan budaya yang ada, meningkatkan partisipasi dan kesadaran masyarakat dalam pengembangangan desa wisata.

\section{DAFTAR PUSTAKA}

Anonim. Undang-Undang RI No. 10 Tahun 2009 Tentang Kepariwisataan

Bungin, Burhan. 2003. Analisis Data Penelitian Kualitatif. Jakarta : PT Grafindo Persada.

Indrawan, Rully. 2014. Metodologi Penelitian Kualitatif, Kuantitatif dan Campuran. Surabaya : Refika Aditama

Mahagangga, I. G. A. O, I Putu Anom dan Ida Ayu Suryasih. 2015. Kajian Pengembangan Desa Wisata Di Kabupaten Badung. Seminar Nasional Sains dan Teknologi (Senastek),Denpasar Bali

Maharini, Dewa Ayu Eka dan I Nyoman Sukma Arida. 2014. Keterlibatan Masyarakat Dalam Pengelolaan Desa Wisata Pangsan di Kabupaten Badung. Denpasar. Jurnal Destinasi Pariwisata Vol. 2 No. 1.

Moleong, Lexy J.2012.Metode Penelitian Kualitatif, Edisi revisi. Bandung : Rosda.

Setiawan, Ida Bagus Dwi dan I Putu Budiarta. 2016. Strategi Pengembangan Desa Bongkasa Pertiwi Kabupaten Badung Sebagai Desa Wisata. Denpasar: Soshum Jurnal Sosial dan Humaniora, Vol. 6, No. 3

Tosun. 1999. Limits to Community Participation in the Tourism Development Process in Development Countries. Pergamon.

Yudasuara, I Ketut. 2015. Pengelolaan Daya Tarik Wisata Berbasis Masyarakat Di Desa Pecatu, Kuta Selatan, Kabupaten Badung. Jurnal Master Pariwisata (Jumpa). 